\title{
Childhood Trauma and Dissociation in Patients with Obsessive Compulsive Disorder
}

\author{
H Belli ${ }^{1}, \mathrm{C}$ Ural $^{1}$, S Yesilyurt ${ }^{2}$, MK Vardar ${ }^{1}$, M Akbudak $^{1}$, F Oncu ${ }^{2}$
}

\begin{abstract}
Background and objective: The present study attempted to assess childhood trauma events and dissociative symptoms in patients with obsessive compulsive disorder (OCD).

Method: The study included all patients who were admitted for the first time to the psychiatric outpatient unit over a 24-month period. Seventy-eight patients were diagnosed as having OCD during the twoyear study period. Childhood traumatic events were assessed with a Childhood Trauma Questionnaire (CTQ). Obsessive compulsive disorder symptoms were assessed with the Yale-Brown Obsessive Compulsive Scale (Y-BOCS). A Dissociation Questionnaire (DIS-Q) was also used to measure dissociative symptoms.

Results: The mean of Y-BOCS points were $23.37 \pm 7.27$. Dissociation questionnaire scores were between 0.40 and 3.87 and the mean was $2.23 \pm 0.76$. Childhood trauma points were 1.27-4.77 and the mean was $2.38 \pm 0.56$. There was no statistically significant relationship between Y-BOCS points and childhood trauma points $(\mathrm{p}>0.05)$. There was a statistically significant positive relationship between $Y$-BOCS points and DIS-Q points. There was no statistically significant relationship between DIS- $Q$ points and childhood trauma points ( $\mathrm{p}>0.05)$.

Conclusion: Childhood trauma questionnaire points might be significant clinically, although there was not a statistically significant correlation in our study. We also conclude that dissociative symptoms among patients with OCD should alert clinicians to treatment of the disorder.
\end{abstract}

Keywords: Childhood trauma, dissociation, obsessive compulsive disorder

\section{Traumas de Infancia y Disociación en Pacientes con Trastornos Obsesivo-Compulsivos}

\author{
H Belli ${ }^{1}$, C Ural ${ }^{1}$, S Yesilyurt ${ }^{2}$, MK Vardar ${ }^{1}$, M Akbudak $^{1}$, F Oncu ${ }^{2}$
}

\begin{abstract}
RESUMEN
Antecedentes y objetivo: El presente estudio tuvo por objeto evaluar eventos traumáticos de la infancia, y síntomas disociativos en pacientes con trastorno obsesivo-compulsivo (TOC).

Método: El estudio incluyó a todos los pacientes que fueron ingresados por primera vez en la Unidad Psiquiátrica, a lo largo de un período de 24 meses. A setenta y ocho pacientes les fue diagnosticado TOC durante un periodo de dos años. Los eventos traumáticos de la infancia fueron evaluados mediante un Cuestionario de traumas de infancia (CTQ). Los sintomas del trastorno obsesivo-compulsivo fueron evaluados mediante la Escala Yale-Brown para el trastorno obsesivo-compulsivo (Y-BOCS). Asimismo, para medir los síntomas disociativos, se usó un Cuestionario de disociación (DIS-Q).

Resultados: Los puntos promedios del cuestionario Y-BOCS fueron 23.37 \pm 7.27. Las puntuaciones del Cuestionario de disociación estuvieron entre 0.40 y 3.87 y la media fue $2.23 \pm 0.76$. Los puntos por trauma de infancia fueron 1.27-4.77 y la media fue 2.38 \pm 0.56 . No hubo relación estadisticamente significativa entre los puntos de Y-BOCS, y los puntos por trauma de la infancia ( $\mathrm{p}>0.05)$. Hubo una relación positiva estadisticamente significativa entre los puntos de Y-BOCS y los puntos de DIS-Q. No hubo una relación estadísticamente significativa entre los puntos de DIS-Q y los puntos por trauma de la infancia $(\mathrm{p}>0.05)$.
\end{abstract}

From: ${ }^{1}$ Bagcilar Education and Research Hospital, Department of Psychiatry, Istanbul, Turkey and ${ }^{2}$ Bakirkoy Mazhar Osman Mental Health and Neurological Diseases Education and Research Hospital, Department of Psychiatry, Istanbul, Turkey.

West Indian Med J 2013; 62 (1): 39
Correspondence: Dr H Belli, Bağcilar Eğitim ve Araştirma Hastanesi, Turkey. Fax: +90 21244040 02, e-mail: hasan.belli@hotmail.com 
Conclusión: Los puntos del Cuestionario de traumas de infancia podrían ser clínicamente significativos, aunque no hubo una correlación estadísticamente significativa en nuestro estudio. También concluimos que los sintomas disociativos entre los pacientes con TOC deben alertar a los clínicos médicos al tratamiento de este trastorno.

Palabras claves: Trauma infancia, disociación, trastorno obsesivo-compulsivo

West Indian Med J 2013; 62 (1): 40

\section{INTRODUCTION}

Dissociation refers to disruptions in the usually integrated functions of consciousness, such as memory, identity and perceptions of the environment. Dissociation has been widely related to traumatic events, in particular to childhood abuse (1, 2 ), emphasizing its function as an autohypnotic defence mechanism to maintain the psychological integrity of the individual (3). It was reported that both somatoform and psychoform dissociations were correlated with childhood trauma $(4,5)$. Of patients with dissociative disorder in Turkey, $46.0 \%$ had childhood physical abuse and in $33.0 \%$, childhood sexual abuse was identified. High sexual abuse rates were detected among patients with pseudoseizures and somatization disorder. High rates were also found in patients with conversion disorder in general (6).

Dissociative disorders may be associated with all psychiatric conditions (7) but especially so in the borderline personality disorder $(8,9)$, conversion disorder $(6)$, and obsessive compulsive disorder [OCD] (10).

Obsessive compulsive disorder is a frequent disorder with a lifetime prevalence rate between 1 and $3 \%$ (1) and is largely a chronic course of illness. This disorder is characterized by recurrent obsessions or compulsions that are severe enough to be time consuming, cause marked distress or lead to significant impairment in the life of the affected individual (American Psychiatric Association, 1994). Psychodynamic traditions say that obsessions and compulsions are generally viewed as a defence mechanism against intolerable drives and wishes (11). Predominantly aggressive feelings and fantasies should be controlled by obsessions and compulsions (12), and often these symptoms also serve as a self-stabilizing mechanism in patients with narcissistic deficits $(13,14)$. However, several lines of evidence also suggest that trauma may play a significant role in the development of $\operatorname{OCD}(15,16)$.

A symptomatological overlap between OCD and dissociation seems to be likely. For instance, both dissociation (17) and $\operatorname{OCD}(18,19)$ are associated with higher scores on the Cognitive Failures Questionnaire (CFQ; 14), a self-report instrument that assesses everyday lapses in attention and memory. Findings linking depersonalization and obsessive tendencies were reported subsequently by Davison (20) and Hollander and Benzaquen (21). Goff et al studied 100 patients with OCD and further characterized a group of the 20 high-dissociative patients with regard to OCD symptom subgroups (22). More severe OCD symptoms were obtained in patients with a higher degree of dissociation (23). A case history of an OCD patient who developed dissociative symptoms during exposure treatment had initiated further research (24). The study suggested that dissociative experiences may have prevented desensitization in this patient during exposure therapy.

We argued that patients with OCD had high levels of dissociation symptoms and had severe childhood traumatic experiences and the level of dissociation could be correlated with the severity of obsessive compulsive symptoms.

\section{SUBJECTS AND METHODS}

All patients admitted for the first time to the psychiatric outpatient unit of the Bagcilar Education and Research Hospital in Istanbul, Turkey, over a 24-month period (January 1, 2008 to December 31, 2010) and who had a clinical diagnosis of OCD were considered for participation in the study. Seventy-eight patients were diagnosed as having OCD during the two-year study period. Patients had to meet DSM-IV criteria for OCD. There were $76.9 \%$ of patients $(n=60)$ who were female and $23.1 \%$ of patients $(n=18)$ were male. They were between 18 and 54 years of age; the average age of the participants was 31.22 years $(\mathrm{SD}=8.83)$. The patients who agreed to participate provided written informed consent after the study procedures had been fully explained.

\section{Instruments}

Childhood Trauma Questionnaire (CTQ): This is a 40-item, five-item Likert scaling-like questionnaire developed by Bernstein et al (25) to scan trauma experience before the age of 18 years. Answer options were given as (1) never, (2) rarely, (3) sometimes, (4) common and (5) very common. High scores implied that abuse was experienced more commonly during childhood or adolescence. In the study by Bernstein et al, the Cronbach alpha coefficient varied between 0.79 and 0.94. The Cronbach alpha coefficient of the scale was found to be $0.96(0.94-0.96)$ for subscales in the validity and safety study by Aslan and Alparslan in Turkey (26). Total score was between 40 and 200. High scores indicate the high frequency of childhood trauma experience.

Dissociation Questionnaire (DIS-Q): This scale, developed by Vanderlinden et al (27), is used to scan dissociative experience and disruptions, and to measure their severity. It can be used for psychiatric patients, individuals with traumatic experience, and for scanning purposes. Its instructions are available in the introduction section of the scale and patients are asked to mark the most appropriate option for their condition. It consists of a total of 63 questions and the subject marks one 
option for each of these questions. Each item is scored between 1 and 5 points, mean score is obtained by dividing total scores by 63 (28). The Cronbach alpha coefficient of the scale - whose study for validity and safety in Turkey was performed by Sar et al - is 0.98 (29). This scale can distinguish the subjects with dissociative disorder from healthy individuals or from patients with schizophrenia or bipolar mood disorder. There is a high correlation between DES score and DIS-Q score $(\mathrm{r}=0.90, p=0.001)$. According to the results of the studies conducted in Turkey, there is a high liability for dissociative disorder in individuals having a total score of 2.5 or above. Yale-Brown Obsessive Compulsive Scale (Y-BOCS): The scale, which was designed by Goodman et al, is used extensively in research and clinical practice to both determine severity of OCD and to monitor improvement without being biased towards the type of obsessions or compulsions present. The scale is a clinician-rated, 10-item scale, each item rated from 0 (no symptoms) to 4 (extreme symptoms). The scale includes questions about the amount of time the patient spends on obsessions, how much impairment or distress they experience and how much resistance and control they have over these thoughts. This scale, which measures obsessions separately from compulsions, specifically measures the severity of symptoms of OCD and monitors improvement during treatment. The same types of questions are asked about compulsions (ie time spent, interference etc). The results can be interpreted based on the final score. A score of $0-7$ is sub-clinical, $8-15$ is mild, $16-23$ is moderate; $24-31$ is severe and $32-40$ is extreme. Patients scoring in the mild range or higher should consider professional help in alleviating obsessive compulsive symptoms (30).

\section{Interview}

Five clinical researchers interviewed patients. Demographic data, including current age, age at onset of the illness, educational level and current employment status were obtained. Childhood traumatic events were assessed with the CTQ. Obsessive compulsive disorder symptoms were assessed with the Y-BOCS. The DIS-Q was also used to measure dissociative symptoms. All interviewers had extensive experience in the administration of the instruments.

\section{Statistical investigations}

NCSS (Number Cruncher Statistical System) 2007 and PASS 2008 Statistical Software (Utah, USA) programme were used for statistical analysis of the study data. While evaluating the study data, in addition to descriptive statistical methods (mean, standard deviation), one-way analysis of variance (ANOVA) test was used for quantitative data comparison between groups in normally distributed parameters, and Student $t$ test was employed for comparisons between two groups. Level of significance was $p<0.05$.

\section{RESULTS}

Seventy-eight patients were diagnosed with OCD during the two-year study period; $76.9 \%$ of patients $(\mathrm{n}=60)$ were female and $23.1 \%(n=18)$ were males. They were between 18 and 54 years of age and the average age was 31.22 years $(\mathrm{SD}=8.83)$. The mean duration of the disorder was $82.47 \pm 67.58$ months (range 2-384 months). Primary school graduates comprised $41 \%$ of the patients $(n=35), 53.8 \%$ of the patients $(n=42)$ were housewives and 71.8\% ( $\mathrm{n}=56)$ were married (Table 1$)$.

Table 1: Education level, occupation and marital status of patients

\begin{tabular}{llcc}
\hline & Min-Max & Mean \pm SD \\
\hline Duration of the disorder (month) & $\begin{array}{c}\mathbf{2 - 3 8 4} \\
\text { N }\end{array}$ & $\begin{array}{c}\mathbf{8 2 . 4 7} \pm \mathbf{6 7 . 5 8} \\
\mathbf{\%}\end{array}$ \\
\hline \multirow{4}{*}{ Education level } & Absent & 2 & 2.6 \\
& Literate & 1 & 1.3 \\
& Primary school & 32 & 41 \\
& Middle school & 15 & 19.2 \\
& High school & 16 & 20.5 \\
& University & 12 & 15.4 \\
& Unemployed & 5 & 6.4 \\
Occupation & Housewives & 42 & 53.8 \\
& Worker & 17 & 21.8 \\
& Civil servant & 2 & 2.6 \\
& Student & 7 & 9 \\
Marital status & Self-employed & 5 & 6.4 \\
& Unmarried & 22 & 28.2 \\
& Married & 56 & 71.8 \\
\hline
\end{tabular}

The mean of Y-BOCS points were $23.37 \pm 7.27$. Dissociation questionnaire scores were between 0.40 and 3.87 and the mean was $2.23 \pm 0.76$. Childhood trauma points were $1.27-4.77$ and the mean was $2.38 \pm 0.56$ (Table 2). There was no statistically significant relationship between Y-BOCS points and childhood trauma points $(p>0.05)$.

Table 2: Distribution of scales score

\begin{tabular}{lcr}
\hline & Min-Max & Mean \pm SD \\
\hline Y-BOCS & $3-40$ & $23.37 \pm 7.27$ \\
DIS-Q & $0.40-3.87$ & $2.23 \pm 0.76$ \\
CTQ & $1.27-4.77$ & $2.38 \pm 0.56$ \\
\hline
\end{tabular}

Y-BOCS - Yale-Brown Obsessive Compulsive Scale, DIS-Q - Dissociation Questionnaire, CTQ - Childhood Trauma Questionnaire

There was a statistically significant positive relationship between Y-BOCS points and DIS-Q points at the level of $27.8 \%(p<0.05)$ [Figure]. There was no statistically significant relationship between DIS-Q points and childhood trauma points $(p>0.05)$.

There was no statistically significant relationship between disease duration and DIS-Q points $(p>0.05)$ and between disease duration and childhood trauma points $(p>0.05)$.

There was no statistically significant difference between gender and Y-BOCS points $(p>0.05)$, gender and DIS-Q points $(p>0.05)$ and gender and childhood trauma points $(p>$ $0.05)$ [Table 3]. 


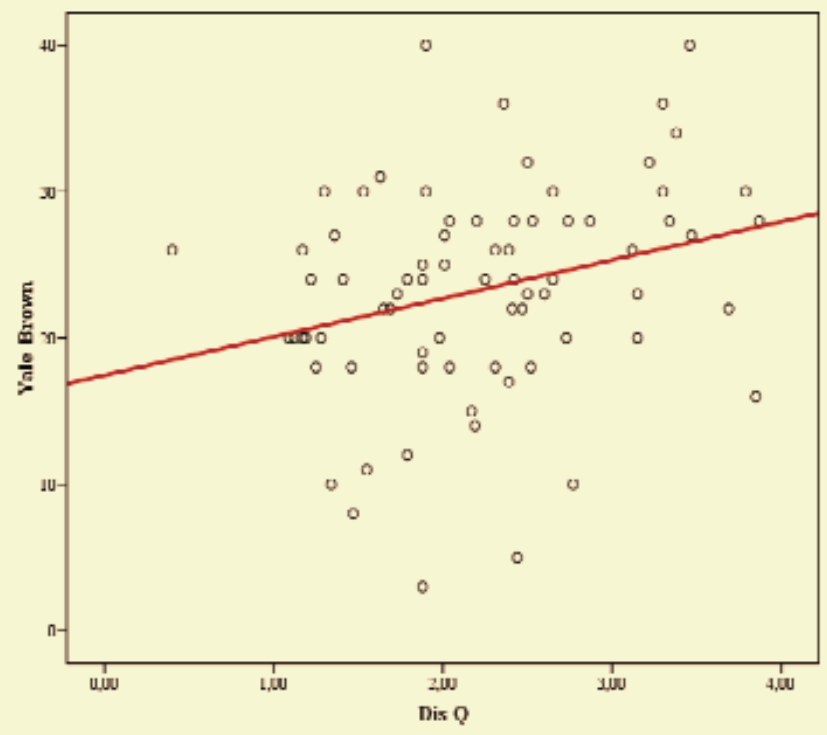

Figure: The relationship between Yale-Brown Obsessive Compulsive Scale and Dissociation Questionnaire.

Table 3: Evaluation of the scales according to sex

\begin{tabular}{lccc}
\hline & $\begin{array}{c}\text { Female }(\mathbf{n}=\mathbf{5 9}) \\
\text { Mean } \pm \text { SD }\end{array}$ & $\begin{array}{c}\text { Male }(\mathbf{n}=\mathbf{1 6}) \\
\text { Mean } \pm \text { SD }\end{array}$ & $\boldsymbol{p}$ \\
\hline Y-BOCS & $23.83 \pm 6.76$ & $21.69 \pm 8.96$ & 0.299 \\
DIS-Q & $2.19 \pm 0.68$ & $2.36 \pm 0.99$ & 0.519 \\
CTQ & $2.38 \pm 0.61$ & $2.39 \pm 0.32$ & 0.942 \\
\hline
\end{tabular}

Student $t$ test was used

Y-BOCS - Yale-Brown Obsessive Compulsive Scale, DIS-Q - Dissociation Questionnaire, CTQ - Childhood Trauma Questionnaire

There was no statistically significant difference between marital status and Y-BOCS points $(p>0.05)$ nor was there a statistically significant difference between marital status and DIS-Q points $(p>0.05)$ and between marital status and childhood trauma points $(p>0.05)$ [Table 4$]$.

Table 4: Evaluation of the scales according to marital status

\begin{tabular}{lccc}
\hline & $\begin{array}{c}\text { Marital status } \\
\text { Unmarried }(\mathbf{n}=\mathbf{2 0}) \\
\text { Mean } \pm \text { SD }\end{array}$ & $\begin{array}{c}\text { Married }(\mathbf{n}=\mathbf{5 5}) \\
\text { Mean } \pm \text { SD }\end{array}$ & $\boldsymbol{p}$ \\
\hline Y-BOCS & $23.35 \pm 8.19$ & $23.38 \pm 6.99$ & 0.987 \\
DIS-Q & $2.26 \pm 0.91$ & $2.22 \pm 0.70$ & 0.856 \\
CTQ & $2.36 \pm 0.41$ & $2.39 \pm 0.61$ & 0.806 \\
\hline
\end{tabular}

Student $t$ test was used

Y-BOCS - Yale-Brown Obsessive Compulsive Scale, DIS-Q - Dissociation Questionnaire, CTQ - Childhood Trauma Questionnaire

There was no statistically significant difference between educational level and Y-BOCS points $(p>0.05)$. Yale-Brown Obessive Compulsive Scale points have been observed to decrease by a small amount while educational level increases.
There was no statistically significant difference between educational level and DIS-Q points $(p>0.05)$. There was also no statistically significant difference between educational level and childhood trauma points $(p>0.05)$ [Table 5].

Table 5: Evaluation of the scales according to education level

\begin{tabular}{|c|c|c|c|c|c|}
\hline & \multicolumn{5}{|c|}{ Education level } \\
\hline & $\begin{array}{c}\text { Primary } \\
\text { school and } \\
\text { lower } \\
(n=35)\end{array}$ & $\begin{array}{l}\text { Middle school } \\
\quad(\mathrm{n}=15)\end{array}$ & $\begin{array}{l}\text { High School } \\
\quad(\mathrm{n}=16)\end{array}$ & $\begin{array}{l}\text { University } \\
\qquad(\mathrm{n}=9)\end{array}$ & $p$ \\
\hline & Mean \pm SD & Mean \pm SD & Mean \pm SD & Mean \pm SD & \\
\hline Y-BOCS & $25.09 \pm 5.46$ & $21.93 \pm 8.83$ & $22.38 \pm 8.15$ & $20.89 \pm 8.72$ & 0.278 \\
\hline DIS-Q & $2.30 \pm 0.73$ & $2.12 \pm 0.66$ & $2.27 \pm 0.97$ & $2.14 \pm 0.71$ & 0.845 \\
\hline CTQ & $2.44 \pm 0.64$ & $2.13 \pm 0.45$ & $2.45 \pm 0.51$ & $2.43 \pm 0.37$ & 0.300 \\
\hline
\end{tabular}

One-way ANOVA test was used

Y-BOCS - Yale-Brown Obsessive Compulsive Scale, DIS-Q - Dissociation Questionnaire, CTQ - Childhood Trauma Questionnaire

\section{DISCUSSION}

The subjects in the present study endorsed DIS-Q scores (mean $=2.23 \pm 0.76$ ) close to that of the DSM-IV dissociative disorder patients in Turkey (mean 3.3). However, these scores are markedly above the means for nonclinical populations in Turkey [mean 1.6] $(31,32)$. Nevertheless, the structured diagnostic interviews in the present study demonstrated that there is considerable overlap between OCD and dissociative disorders. The mean of Y-BOCS points was $23.37 \pm 7.27$ in our study. This mean score was approximately at severe level [1623 is moderate, $24-31$ is severe] (30). There was a statistically significant positive relationship between Y-BOCS points and DIS-Q points in our study. Raszka et al (33) suggested that the level of psychological dissociation is associated with the severity of anxiety symptoms rather than with obsessive compulsive symptoms. Dissociation might be a negative predictor of treatment outcome in cognitive-behaviour therapy for patients with anxiety disorders (34). More severe OCD symptoms after cognitive-behaviour therapy were associated with higher dissociative level at baseline, and treatment nonresponders had a significantly higher baseline dissociative level compared to responders (23). High level of dissociation may be one of the reasons for treatment resistance in patients suffering from OCD (35).

Childhood trauma points were 1.27-4.77 and the mean was $2.38 \pm 0.56$. There was no statistically significant relationship between Y-BOCS points and childhood trauma points nor between DIS-Q points and childhood trauma points in our study. The patients with OCD reached levels of psychological dissociation assessed by the DIS-Q. Although there was a positive correlation between psychological dissociation symptoms and OCD symptoms or severity, there was no correlation between childhood trauma points and dissociative symptom points in our study. A study in Turkey demonstrated that DIS- 
Q points were correlated with CTQ points. Patients were diagnosed with conversion disorder in this study (36). Some researchers revealed that the severity of dissociation measured by scales predicted the high level of childhood traumatic experience points in patients with psychiatric disorders $(37,38)$. Although there was no statistically significant correlation in our study, CTQ points might be significant clinically. The average rate detected in our study $(2.38 \pm 0.56)$ was not negligible. At least some cases of severe traumatic experiences were detected. Given a larger sample group, this rate could have been higher. Therefore, traumatic experiences should not be overlooked in patients with OCD. In addition, the relationship between traumatic experiences and dissociative phenomena should be taken into account.

Cognitive-behavioural models argued that negative appraisal of the obsessional thought was the key factor in thought escalation and persistence. Salkovskis et al argued that thoughts gave rise to active resistance when they activated the overvalued beliefs that (a) thoughts could cause harm and (b) that the individual was honour-bound to prevent harm, even if his/her responsibility for harm or to the potential victim of harm was remote, minute and uncertain. Thus, the individual had to control thoughts which signified a potential harm in order to avert harm and the aversive sense that one might become responsible for harm otherwise $(39,40)$. In addition to therapies on cognitive-behavioural models, for the treatment of dissociative phenomena, differents methods can be used. For example, some authors reported that ego state therapy and hypnotherapy could be effective on the dissociative process (41-43). However, some authors also found a trend towards high-dissociative OCD patients being more likely to be "checkers" than low dissociative OCD patients, although both groups did not differ in prevalence of 'washing' compulsions or obsessions. Amnestic dissociation may trigger checking compulsions, because patients with more pronounced symptoms of this type of dissociation might be less able to remember exactly what action they took in a particular situation (23). In addition, such patients who were diagnosed with checking compulsion should be taken into consideration in the treatment process.

Given the prevalence of OCD, the importance of looking at the different dimensions of this disorder should be understood. One of the important parameters may be the dissociative process. To understand the effects of this process, more indepth, comprehensive studies should be done. We conclude that dissociative symptoms among patients with OCD should alert clinicians to the treatment of the disorder. The predominance of obsessive compulsive symptoms in admission should not lead the clinician to overlook the underlying dissociative process among these patients. However, a lack of adequate response to cognitive-behavioural and drug therapy may be a consequence of the dissociative process.

Limitations of our study are the small sample size, which made it impossible to evaluate different subgroups of obsessive compulsive disorders and its cross-sectional nature. An- xiety and depression levels were not investigated. Studies with larger numbers of patients are required.

\section{REFERENCES}

1. Zlotnic C, Shea MT, Pearlstein T, Simpson E, Costello E, Begin A. The relationship between dissociative symptoms, alexithymia, impulsivity, sexual abuse and self-mutilation. Compr Psychiatry 1996; 37: 12-6.

2. Zlotnic C, Shea MT, Zakriski A, Costello E, Begin A, Pearlstein T. Stressors and close relationship during childhood and dissociative experiences in survivors of sexual abuse among inpatient psychiatric women. Compr Psychiatry 1995; 36: 207-12.

3. Cardena E. The domain of dissociation. In: Lynn SJ, Rhue JW, eds. Dissociation. Clinical and Theoretical Perspectives. New York: Guilford Press; 1994: 15-31.

4. Chu JA, Dill D. Dissociative symptoms in relation to childhood physical and sexual abuse. Am J Psychiatry 1990; 147: 887-92.

5. Kisiel CL, Lyons JS. Dissociation as a mediator of psychopathology among sexually abused children and adolescents. Am J Psychiatry 2001; 158: 1034-9.

6. Sar V, Akyuz G, Kundakci T, Kiziltan E, Dogan O. Childhood trauma, dissociation, and psychiatric comorbidity in patients with conversion disorder. Am J Psyciatry 2004; 161: 2271-6.

7. Sar V, Ross C. Dissociative disorders as a confounding factor in psychiatric research. Psychiatr Clin North Am 2006; 29: 129-44.

8. Sar V, Kundakci T, Kiziltan E, Dogan O. The axis-I dissociative disorder comorbidity of borderline personality disorder among psychiatric outpatients. J Trau Dissociat 2003; 4: 119-36.

9. Sar V, Akyuz G, Kugu N, Ozturk E, Ertem-Vehid H. Axis I dissociative disorder comorbidity in borderline personality disorder and reports of childhood trauma. J Clin Psychiatry 2006; 67: 1583-90.

10. Rufer M, Held D, Cremer J, Fricke S, Moritz S, Peter H et al. Dissociation as a predictor of cognitive behavior therapy outcome in patients with obsessive-compulsive disorder. Psychother Psychosoms 2006; 75: 40-6.

11. Freud S. Hemmung, Symptom und Angst. In: Freud A, ed. Sigmund Freud. Gesammelte Werke. Chronologisch geordnet. London: Imago; 1948: vol 14.

12. Csef H. Zur Psychosomatik des Zwangskranken. Berlin: Springer; 1988.

13. Thiel A, Schüssler G. Zwangssymptome bei strukturellen Selbst-Defekten-Eine Untersuchung am Beispiel der Anorexia und Bulimia Nervosa. Z Psychosom Med Psychoanal 1995; 41: 60-76.

14. Mentzos S: Neurotische Konfliktverarbeitung. Frankfurt: Fischer; 1984.

15. Marks IM. Phobias, and rituals: panic, anxiety, and their disorders. New York: Oxford University Press; 1987.

16. Solomon Z, Bleich A, Koslowsky M, Kron S, Lerer B, Waysman M. Post-traumatic stress disorder: issues of co-morbidity. J Psychiatr Res 1991; 25: 89-94.

17. Mercekbach H, Muris P, Rosin E. Fantasy proneness and cognitive failures as correlates of dissociative experiences. Person and Individual Differences 1999; 26: 961-7.

18. Broadbent DE, Broadbent MHP, Jones JL. Performance correlates of selfreported cognitive failure and of obsessionality. Br J Clin Psychology 1986; 25: 285-99.

19. Sher KJ, Mann B, Frost RO. Cognitive dysfunction in compulsive checkers, further explorations. Behav Res Ther 1984; 5: 493-502.

20. Davison K. Episodic depersonalization; observation on seven patients. $\mathrm{Br}$ J Psychiatry 1964; 10: 505-13.

21. Hollander E, Benzaquen S. The obsessive-compulsive spectrum disorders. Int Rev Psychiatry 1997; 9: 99-110.

22. Goff DC, Olin JA, Jenike MA, Baer L, Buttolph ML. Dissociative symptoms in patients with obsessive-compulsive disorder. J Nerv Ment Dis 1992; 180: 332-7.

23. Rufer M, Fricke S, Held D, Cremer J, Hand I. Dissociation and symptom dimensions of obsessive-compulsive disorder: a replication study. Eur Arch Psychiatry Clin Neurosci 2006; 256: 146-50.

24. Bartlett AE, Drummond LM. Hysterical conversion and dissociation arising as a complication of behavioural psychotherapy treatment of obsessive-compulsive neurosis. Br J Med Psychol 1990; 63: 109-15. 
25. Bernstein DP, Fink L, Handelsman L, Foote J, Lovejoy M, Wenzel K et al. Initial reliability and validity of a new retrospective measure of child abuse and neglect. Am J Psychiatry 1994; 151: 1132-6.

26. Aslan SH, Alparslan ZN. Validity, safety and factorial structure of Childhood Trauma Questionnaire in a sample of university students. Turk Psikiyatri Dergisi 1999; 10: 275-85.

27. Vanderlinden J, Van Dyck R, Vandereycken W, Vertommen H, Verkes RJ. The Dissociation Questionnaire (DIS-Q). Development and characteristics of a new self reporting questionnaire. Clin Psychol Psychother 1993; 1: $21-7$.

28. Svedin CG, Nilsson D, Lindell C. Traumatic experiences and dissociative symptoms among Swedish adolescents. A pilot study using Dis-QSweden. Nord J Psychiatry 2004; 58: 349-55.

29. Sar V, Kiziltan E, Kundakci T, Bakim B, Yargic LI. Validity and safety of Dissociation Questionnaire. $33^{\text {rd }}$ National Psychiatry Congress Full TextBooklet. Antalya, Turkey; 1997 (Dissosiyasyon olceginin gecerlilik ve guvenilirligi, 33. Ulusal Psikiyatri KongresiTam Metin Kitabi, Antalya Turkiye).

30. Goodman WK, Price LH, Rasmussen SA, Mazure C, Fleischmann RL, Hill CL et al. The Yale-Brown Obsessive Compulsive Scale. I. Development, use, and reliability. Arch Gen Pychiatry 1989; 46: 1006-11.

31. Sar V, Kundakçi T, Kiziltan E, Bakim B, Bozkurt O. Differentiating dissociative disorders from other diagnostic groups through somatoform dissociation in Turkey. J Trauma Dissoc 2000; 1: 67-80.

32. Sar V, Kiziltan E, Kundakçi T, Bakim B, Yargic LI, Bozkurt O. The reliability and validity of the Turkish version of the Dissociation Questionnaire (DIS-Q) [Abstract] Presented at the $15^{\text {th }}$ Fall Meeting of the International Society for the Study of Dissociation. Northbrook, Illinois, USA, 1998.

33. Raszka M, Praško J, Kopřivová J, Novák T, Adamcová K. Psychological dissociation in obsessive-compulsive disorder is associated with anxiety level but not with severity of obsessive-compulsive symptoms. Neuroendocrinol Lett 2009; 30: 624-8.
34. Spitzer C, Barnow S, Freyberger HJ, Grabe HJ. Dissociation predicts symptom-related treatment outcome in short-term inpatient psychotherapy. Aus N Z J Psychiatry 2007; 41: 682-7.

35. Praško J, Raszka M, Adamcová K, Grambal A, Kopřivová J, Kudrnovská $\mathrm{H}$ et al. Predicting the therapeutic response to cognitive behavioural therapy in patients with pharmacoresistant obsessive-compulsive disorder. Neuroendocrinol Lett 2009; 30: 615-23.

36. Ozcetin A, Belli H, Ertem U, Bahcebasi T, Ataoglu A, Canan F. Childhood trauma and dissociation in women with pseudoseizure-type conversion disorder. Nord J Psychiatry 2009; 63: 462-8.

37. Sar V, Akyüz G, KundakçiT, Dogan O. Prevalence of trauma-related disorders in Turkey: an epidemiological study [Abstract]. Presented at the $14^{\text {th }}$ Annual Meeting of the International Society for Traumatic Stress Studies. Northbrook, Illinois, USA; 1998.

38. Simeon D, Guralnik O, Schmeidler J, Sirof B, Knutelska M. The role of childhood interpersonal trauma in depersonalization disorder. Am J Psychiatry 2001; 158: 1027-33.

39. Salkovskis PM, Richards HC, Forrester E. The relationship between obsessional problems and intrusive thoughts. Behav Cog Psychother 1995; 23: 281-99.

40. Salkovskis PM, Wroe AL, Gledhill A, Morrison N, Forrester E, Richards $\mathrm{C}$ et al. Responsibility, attitudes and interpretations characteristic of obsessive-compulsive disorder. Behav Res Ther 2000; 38: 347-72.

41. Frederick C. Selected topics in ego state therapy. Int J Clin Exp Hypn 2005; 53: 339-429.

42. Frederick C. Hypnotically facilitated treatment of obsessive-compulsive disorder: can it be evidence-based? Int J Clin Exp Hypn 2007; 55: 189 206.

43. Ross CA, Anderson G. Phenomenological overlap of multiple personality disorder and obsessive-compulsive disorder. J Ner Ment Dis 1988; 176: $295-9$. 